\title{
Evidence for Global Coupling of Phytoplankton and Atmospheric Aerosols.
}

\author{
R. A. Cropp and A. J. Gabric \\ Faculty of Environmental Science, Griffith University, Nathan, 4111, Australia. \\ r.cropp@grifffith.edu.au; a.gabric@griffith.edu.au
}

\begin{abstract}
Biological coupling between the ocean and atmosphere may have profound implications for global climate change. Atmospheric aerosols such as dust can directly influence the radiative balance of the earth, but evidence is accumulating to suggest it may also have more subtle effects. Biologically available iron in dust, for example, may stimulate phytoplankton biooms, which then draw down carbon dioxide and emit dimethylsulphide (DMS) to the atmosphere. The latter reacts to form methanesulphonate aerosols (MSA) that may also influence the radiation budget. Such coupling processes have been demonstrated in mesoscale experiments in two HNLC regions of ocean. We present a global analysis of remote sensed data that suggests coupling between phytoplankton and atmospheric aerosols may be more widespread in the world's oceans than previously thought. Collocation of clusters of covarying phytoplankton and aerosols with physical processes is compelling evidence for close biological coupling of ocean and atmosphere.
\end{abstract}

\section{INTRODUCTION}

Aerosol optical depth (AOD) may be used to infer the presence of dust and other particles such as sea salt, smoke and industrial pollution in the atmosphere. Aerosols directly affect the radiation budget of the Earth, and may also indirectly influence climate through interactions with oceanic biota. On a global scale, aeolian transport of mineral dust to the ocean provides a significant proportion of iron $(\mathrm{Fe})$, a nutrient essential for oceanic primary production [1]. Mineral dust from uplifted soils is currently estimated to be about $2150 \mathrm{Tg} \mathrm{yr}^{-1}$, and contributes about $40 \%$ of primary particle emissions to the atmosphere [2].
Mesoscale iron enrichment experiments: IronEx I [3], IronEx II [4] and SOIREE [5] have confirmed significant primary production increases 3-5 days after surface inputs of iron. Iron fertilisation has also promoted the production of the volatile, biogenic compound dimethylsulfide (DMS), with a 3-fold increase in DMS concentrations 5-10 days after the phytoplankton bloom reported during the IronEx I and II experiments [6]. Atmospheric sulfate aerosols, such as those derived from DMS, are important due to their potential impact on the global climate [7]. Emissions of DMS from the oceans to the atmosphere are estimated to be between 13 and $36 \mathrm{TgS} \mathrm{yr}^{-1}$ [8]. This accounts for at least $50 \%$ of natural emissions from ocean, plants and soils taken together. The total natural sulfur flux is estimated to be of the same order of magnitude as the anthropogenic sulfur emissions, mainly from fossil fuel combustion, which are currently estimated at 67.4 TgS $^{-1}{ }^{-1}[9]$.

Here we analyse a four-year global archive of SeaWiFS CHL and AOD data. The computed correlations of the time series of $\mathrm{CHL}$ and $A O D$ formed spatial clusters corresponding to major physical processes such as dust transportation pathways, fluvial discharges, and ocean upwelling areas. The spatial collocation is strong evidence for widespread influence of the deposition of aeolian nutrients on phytoplankton biomass. However, analysis of residual $\mathrm{CHL}$ and $\mathrm{AOD}$ data suggests that other interactions between phytoplankton and atmospheric aerosols are also occurring, which may be evidence of the impact of DMS derived aerosols on $A O D$. 


\section{METHODS}

We analysed four years (1998-2001) of SeaWiFS weekly level 3 binned data (184 data sets) of global chlorophyll a concentration (CHL) and aerosol optical depth $(A O D)$. Relating variables measured in the oceans to variables measured in the atmosphere is problematic due to the vastly different time scales of advection and diffusion in the atmosphere and the ocean. We approached this problem by binning the data into eight-day temporal and one-degree spatial bins. The temporal binning reflects the measured time lag between iron fertilization and the initiation of a phytoplankton bloom [5], and between a bloom and ventilation of DMS to the atmosphere [6]. Data for each week were spatially mapped as averages of one-degree squares.

Correlation coefficients of the resultant time series were calculated for 36,275 one-degree squares that contained twenty or more weeks of data. This was $87 \%$ of ocean one-degree squares, representing $97 \%$ of the global ocean by area. All degree squares with insufficient data were located in polar regions where data was sparse due lack of sunlight in winter and persistent cloud.

Residual data were calculated by sequentially differencing the raw time series for each degree square to remove seasonal effects. The differencing scheme was chosen to reflect whether $\mathrm{CHL}$ and $\mathrm{AOD}$ were covarying compared to their values in the previous week, rather than in respect to some long-term average. A residual correlation coefficient was calculated for each degree square with a raw correlation.

\section{RESULTS AND DISCUSSION}

The Sahara Desert is the largest source of dust emissions to the atmosphere on the globe [10,11]. The westward dust paths from the Sahara can account for up to $50 \%$ of the dust exported from the Sahara [12], taking dust to the Caribbean [13] and southeast USA [14] in summer, and South America $[15,16]$ in winter. These pathways are evident and clearly distinguished in Fig. 1 by regions of high positive correlations.

Dust pathways emanating from China and crossing the North Pacific Ocean [12] are also coincident with regions of high positive correlations. Asian dust plumes may be transported great distances, as the major Asian dust source, the Taklamakan Desert, is located at high altitude [18]. The annulus of high positive correlations centred on about $30^{\circ} \mathrm{N}$, $180^{\circ} \mathrm{E}$ and occupying most of the North Pacific basin, may therefore be the result of dust emanating from China and circulating around the basin [1]. Dust emanating from small dust sources in southwest North America may enhance dust concentrations in the southern arm of the annulus [10].

A patch of high correlation in the South Atlantic northeast of Namibia also underlies a known dust path, where dust originating in the Etosha Pan in Namibia is carried by south-east trade winds over the ocean [18]. A further area of high positive correlation is evident in the Indian Ocean southeast of the Saudi Arabian, Kenyan and Somalian coasts. The horn of Africa is a well-known dust region [10], although transport to the southeast of Kenya and Somalia is a less well-documented dust pathway [18].

Regions of ocean in which phytoplankton biomass is controlled by riverine inputs or ocean upwellings, might be expected to show no evidence of positive correlations between $\mathrm{CHL}$ and AOD. The Mauritanian upwelling is the most powerful and persistent ocean upwelling on the globe [19], and is coincident with a region of near-zero correlation coefficients in Fig. 1. The major upwelling region off the coast of Peru [20] is also coincident with an area of nearzero correlation in Fig. 1, as are upwellings along the west U.S.A. [21, 22] and Benguelan coasts [23].

The discharge of the Amazon River, and subsequent advection of river water northwest in the Guiana Current, is clearly discernible as a patch of negative correlations in Fig. 1. Effects of advected Amazon discharge have been detected as enhanced plankton production at Barbados [24]. 


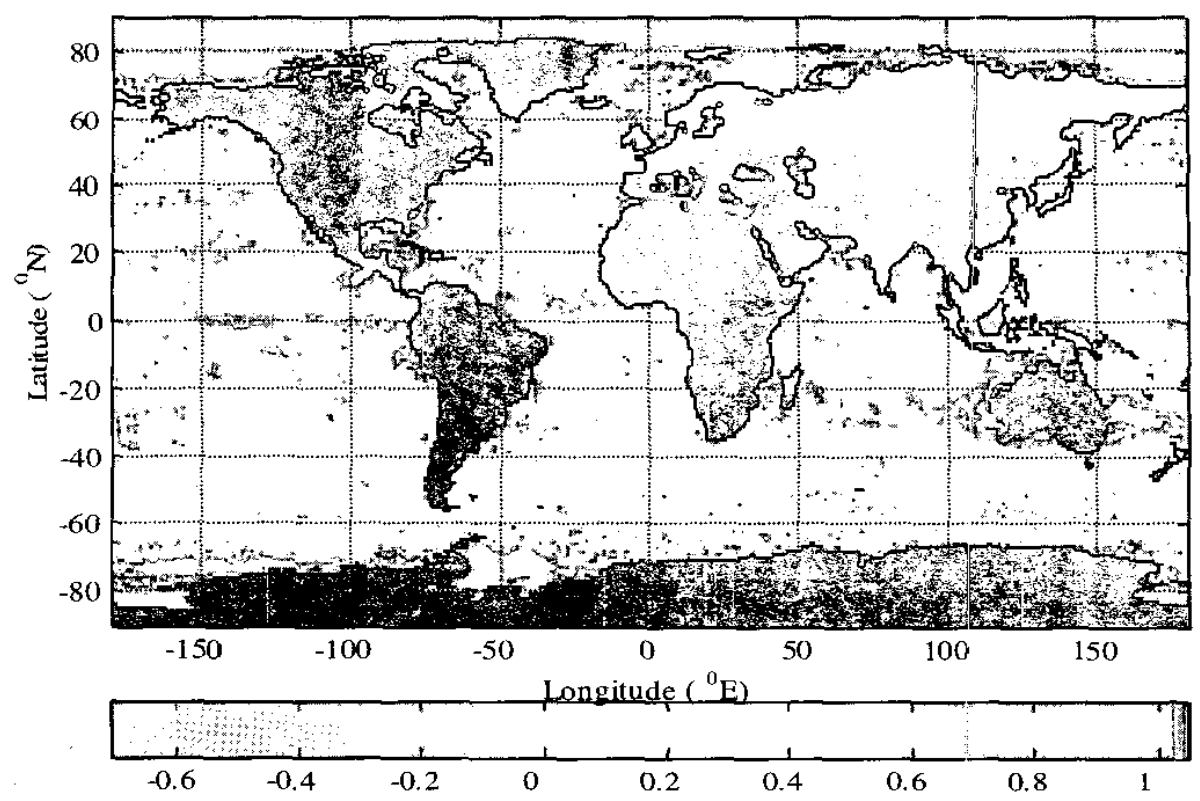

Fig. 1 Correlation coefficients of SeaWiFS CHL with AOD for ocean one-degree squares for $1998-2001$. Black represents land and grey missing data.

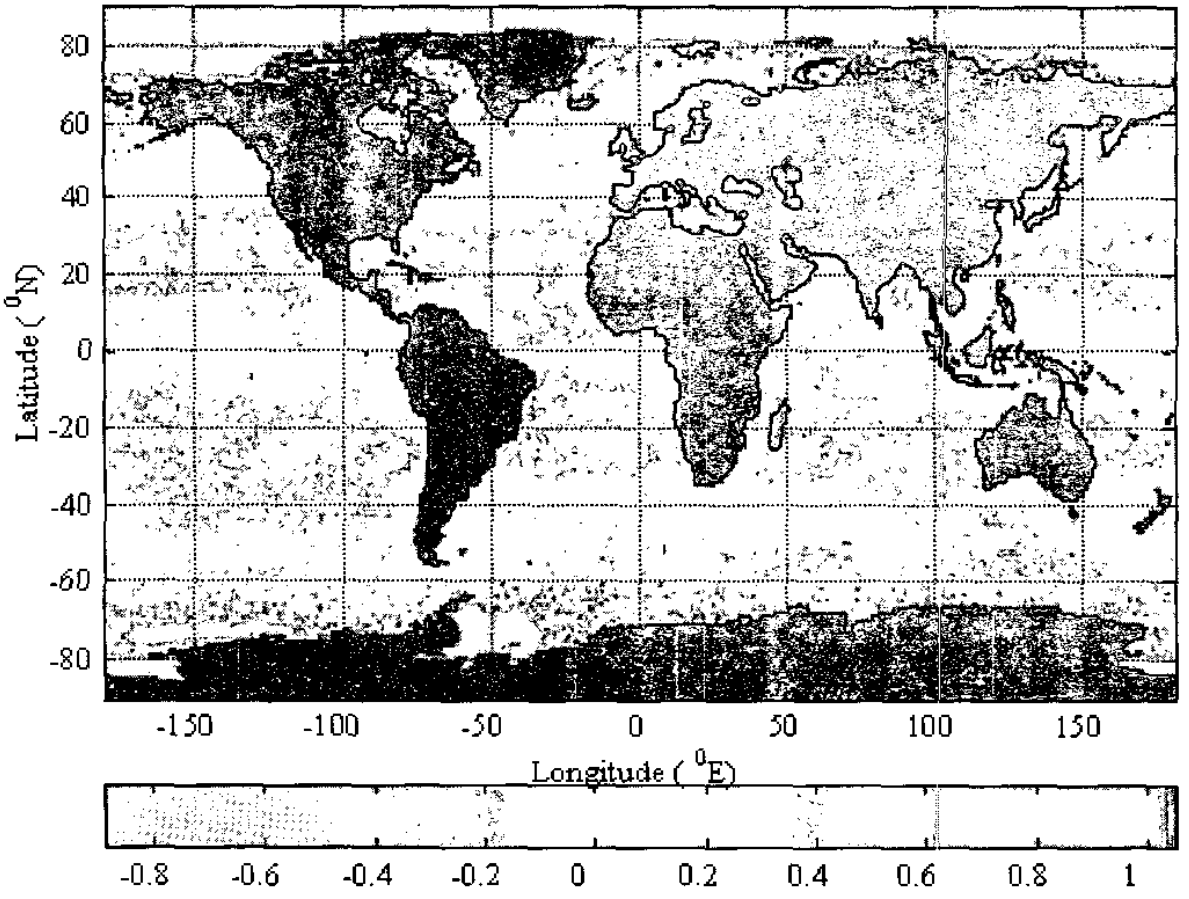

Fig. 2: Correlation coefficients of residuals of SeaWiFS CHL with AOD for ocean one-degree squares for 1998-2001. Black represents land and grey missing data. 
Effects of the Mississippi discharge on phytoplankton in the Gulf of Mexico is also evident in Fig. 1, and appears of a similar scale to documented effects [25]. Small areas of negative correlations are also apparent at the mouths of the La Plata, Irrawaddy and Yangtze Rivers.

The region of negative correlation in the Mediterranean Sea may be attributable to interactions of dust from. the Sahara [10] with atmospheric pollutants from Europe. A clearly defined region of negative correlation off the Pacific Coast of Central America may be the result of seasonal biomass burning practiced extensively in Central America [26].

The positive correlations in the Southern Ocean, and the region of negative correlations surrounding Australia have no obvious link with atmospheric or oceanic features. The spatial extent of the cluster around Australia however agrees remarkably well with the distribution of quartz sediments deposited in the Late Pleistocene in the oceans around Australia [27]. The Australian region may reflect contemporary Aeolian transport and deposition of quartz particles that are, in the context of this study, relatively inert.

The clear spatial clustering of correlation coefficients evident in Fig. 1, and the collocation of positive clusters with physical features such as dust transport pathways, and negative clusters with river discharges and ocean upwellings, is compelling evidence that the correlations are differentiating important coupling processes. The positive correlations are statistically significantly (with $99.9 \%$ confidence) for $28 \%$ of the area of the global oceans.

The effects of seasonal variations of physical forcings were removed by taking the residuals of the $\mathrm{CHL}$ and $\mathrm{AOD}$ data. The residual correlation map (Fig. 2) is striking in that it indicates that $\mathrm{CHL}$ and $\mathrm{AOD}$ are significantly positively correlated in most of the tropical and temperate oceans. At $99.9 \%$ confidence level, over $48 \%$ of the global oceans are positively correlated, while only $0.1 \%$ are negatively correlated, the amount expected from random variation. The effects of some physical forcings, such as the Amazon River and the Peruvian upwelling are still obvious in the residuals, but now as regions of zero correlation.

The distributions of the percentage of ocean area significantly correlated at the $99.9 \%$ confidence level at each latitude for the raw and residual data are presented in Fig. 3. Modes representing latitude zones in which substantial proportions of ocean have significant raw positive correlations (Fig. 3a) are" associated with zones including major dust transport pathways. Up to $67 \%$ of the Southern Ocean has a significant positive correlation, in contrast to previous attempts to correlate chlorophyll with other parameters in the Southern Ocean [28, 29].

The latitudinal distribution of ocean area with significant positive residual correlations (Fig. 3b) reveals an essentially symmetric bimodal distribution. Modes where $95 \%$ of the ocean zone has significant positive correlations between $\mathrm{CHL}$ and $\mathrm{AOD}$ are centred on about $25^{\circ}$ latitude in each hemisphere. These latitudes coincide with zones of dry down-welling air associated with Hadley and Ferrell cells that contribute to atmospheric general circulation [30].

The symmetry of these modes is remarkable given the fundamental differences between the Northern and Southern Hemispheres. Primary particle emissions of organic matter and black carbon from fossil fuels are estimated to be $34.9 \mathrm{Tg} \mathrm{yr}^{-1}$ in the $\mathrm{NH}$, compared to $0.5 \mathrm{Tg}$ $\mathrm{yr}^{-1}$ in the $\mathrm{SH}$. Mineral dust emissions are likewise $1,800 \mathrm{Tg}$ $\mathrm{yr}^{-1}$ compared to $349 \mathrm{Tg} \mathrm{yr}^{-1}$, while sea salt emissions are similar in both hemispheres $\left(1,440 \mathrm{cf} .1,900 \mathrm{Tg} \mathrm{yr}^{-1}\right)$ [2]. The $\mathrm{NH}$ also contains more land, more coastline and more large rivers than the $\mathrm{SH}$, all of which may affect $\mathrm{CHL}$ concentrations. In contrast, the SH has the Southern Ocean, with more ocean at higher latitudes, the majority of the globe's HNLC ocean, and the only circumpolar current. 
(a)

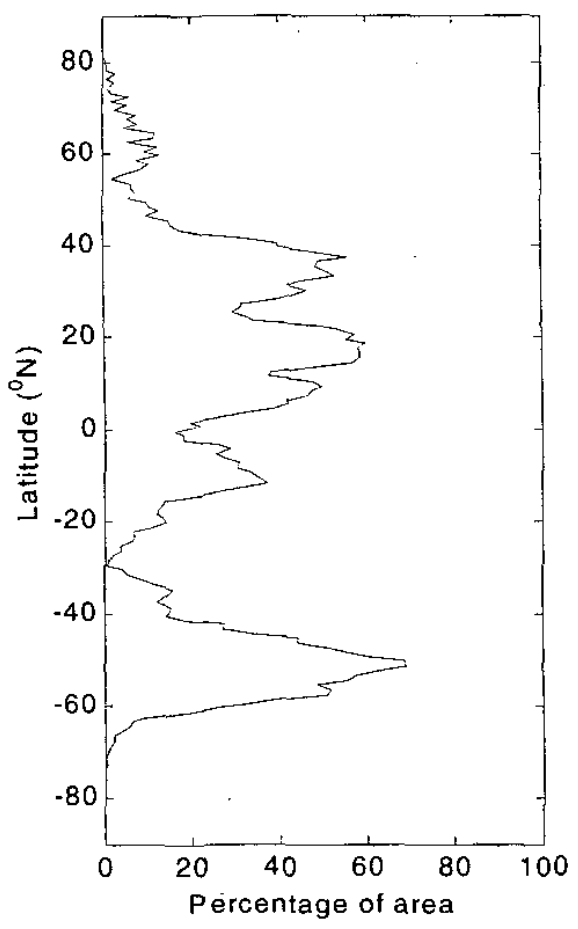

(b)

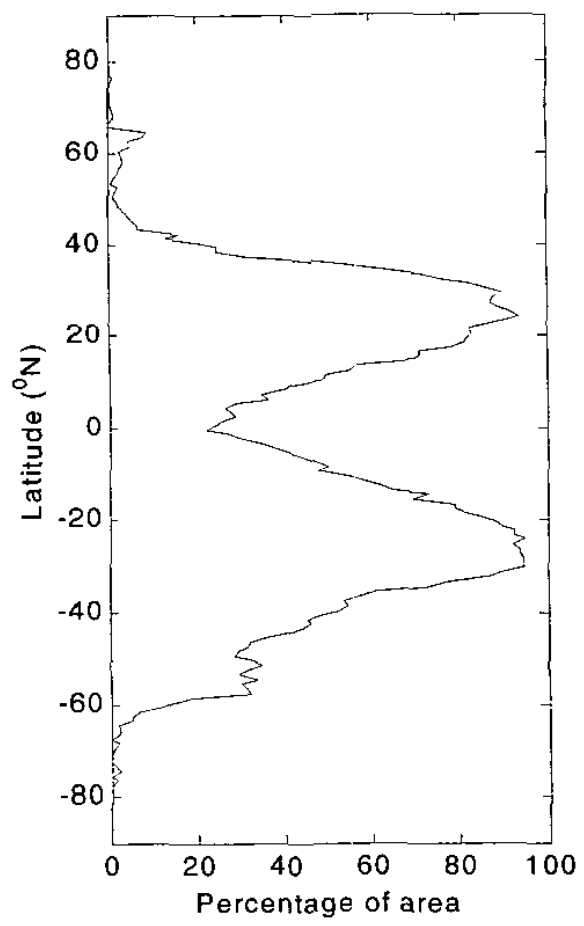

Fig. 3: Latitudinal distribution of the percentage of ocean area for which $\mathrm{CHL}$ and $\mathrm{AOD}$ data is significantly correlated at the $99.9 \%$ confidence level for raw (a) and residual (b) data.

The Southern Ocean is apparent as a small mode countering the general trend of decreasing percentage of positively correlated ocean as latitude increases above $30^{\circ}$. The differences between the distributions of raw and residual correlations in Fig. 3 suggest that although dust deposition to the ocean is a major factor controlling phytoplankton biomass, other mechanisms are also apparent. Dimethylsuiphide (DMS) is a potential coupling between phytoplankton and the atmosphere [7]. Global DMS fluxes from the ocean to the atmosphere are about 13-36 $\mathrm{TgS}^{-1} \mathrm{r}^{-1}$ [8]. Emissions vary with latitude and seasonally, with high summer and low winter emissions per unit area in polar latitudes, and lower emissions yearround in temperate and tropical oceans; however zonally integrated fluxes of.DMS to the atmosphere are also symmetric about the equator.

\section{CONCLUSION}

We correlated global time series of satellite-sensed chlorophyll a, a measure of phytoplankton biomass, and aerosol optical depth, a measure of the atmospheric aerosol loading, as measured by the SeaWiFS satellite sensor. Spatial correlations of contemporaneous data revealed zero correlations, but correlations of time series at discrete locations revealed statistically significant correlations at the $99.9 \%$ confidence level. Five distinct regions of significant positive correlations between $A O D$ and $\mathrm{CHL}$ are evident in a global image of the correlation coefficients (Fig. 1). Four of these coincide spatially with major dust transportation pathways. 
We have presented compelling evidence that $\mathrm{CHL}$ and AOD are closely coupled over much of the global oceans. The very clear spatial clustering of correlation coefficients, which become evident only when $\mathrm{CH}$ and $A O D$ are correlated over time at discrete locations, support our initial assumption that the effects of the different spatial and temporal scales of advection and diffusion in the ocean and atmosphere could be controlled by judicious spatial and temporal averaging. We note however that the averaging regime adopted may not be optimal for high latitudes due to the larger magnitudes of atmospheric advection and diffusion in these regions, resulting in an apparent absence of coupling between $\mathrm{CHL}$ and. $\mathrm{AOD}$ at high latitudes.

\section{Acknowledgments}

The authors would like to thank the SeaWiFS Project (Code 970.2) and the Distributed Active Archive Center (Code 902) at the Goddard Space Flight Center, Greenbelt, MD 20771, for the production and distribution of the satellite data respectively. These activities are sponsored by NASA's. Mission to Planet Earth Program. We would also like to thank the Queensland Parallel Super-computing Facility at Griffith University for the provision of computing facilities, and Kenn Tews for assistance with data processing.

\section{REFERENCES}

[1] Duce, R. A. \& Tindale, N. W. Atmospheric transport of iron and its deposition in the ocean. Limnol. Oceanogr. 36, 17151726 (1991)

[2] Penner, J. E. in Encyclopedia of Global Environmental Change, Volume 1, The Earth system: physical and chemical dimensions of global environmental change. (eds. MacCracken, M. C. \& Perry, J. S.) (John Wiley and Sons, Chichester, 2000).

[3] Martin, J. H., Coale, K. H., Johnson, K. S. \& al, e. Testing the iron hypothesis in ecosystems of the equatorial Pacific Ocean. Nature 371, 123-129 (1994).
[4] Coale, K. H. et al. A massive phytoplankton bloom induced by ecosystem-scale iron fertilization experiment in the equatorial Pacific Ocean. Nature 383, 495-501 (1996).

[5] Boyd, P. W. et al. A mesoscale phytoplankton bloom in the Southern Ocean stimulated by iron fertilization. Nature 407, 695 $702(2000)$

[6] Turner, S. 'M., Nightingale, P. D., Spokes, L. J., Liddicoat, M. I. \& Liss, P. S. Increased dimethylsulphide concentrations in sea water from in situ iron enrichment. Nature 383, 513-517 (1996)

[7] Charlson, R. J., Lovelock, J. E., Andrae, M. O. \& Warren, S. G. Oceanic phytoplankton, atmospheric sulphur, cloud albedo and climate. Nature 326, 655-661 (1987).

[8] Kettle, A. J. and Andreae, M. O. Flux of dimethylsulfide from the oceans: A comparison of updated data sets and flux models. J. Geophys. Res. 105, 26,703-26,808 (2000).

[9] Benkovitz, C. M., et al. 1996. Global gridded inventories of anthropogenic emissions of sulfur and nitrogen. J. Geophys.. Res., 101D, 29239-29253.

[10] Prospero, J. M., Ginoux, P., Torres, O., Nicholson, S. E. \& Gill, T. E. Environmental characterisation of global sources of atmospheric soil dust identified with the NIMBUS-7 TOMS absorbing aerosol product. Reviews of Geophysics (in press).

[11] Goudie, A. S. \& Middleton, N. J. Saharan dust storms: nature and consequences. Earth-Science Reviews 56, 179-204. (2001).

[12] D'Almeida, G. A. A model for Saharan dust transport. J. Climate App. Meteor.. 25, 903-916 (1986).

[13] Prospero, J. M. \& Nees, R. T. Impact of North African drought and El Nino on mineral dust in the Barbados trade winds. Nature 320, 570-572. (1996).

[14] Prospero, J. M. Long-term measurements of the transport of African mineral dust to the southeastern United States: Implications for regional air quality. J. Geophys. Res. 104, $15,917-15,927$ (1999).

[15] Swap, R., Garstang, M., Greco, S., Talbot, R. \& Kallberg, P. Sahara dust in the Amazon basin. Tellus 44, 133-149 (1992).

[16] Prospero, J. M., Glaccum, R. A. \& Nees, R. T. Atmospheric transport of soil dust from Africa to South America Nature 289, 570-572 (1981). 
[18] Ginoux, P. et al. Sources and distributions of dust aerosols simulated with the GOCART model. J. Geophys. Res. 106 D17, $20,255-20,273$ (2001).

[19] Gabric, A. J. et al. Offshore Export Of Shelf Production In The Cape Blanc (Mauritania) Giant Filament As Derived From Coastal Zone Color Scanner Imagery. J. Geophys. Res. 98, 4697-4712 (1993).

[20] Brink, K. H., Halpern, D. \& Smith, R. L. Circulation in the Peru upwelling system near 15 deg. S. J. Geophys. Res. 85, 4,036-4,048. (1980).

[21] Huyer, A. Coastal upwelling in the California system. Prog. Oceanog. 12, 259-284 (1983).

[22] Huyer, A. A comparison of upwelling events in two locations: Oregon and northwest Africa. Journal of Mar. Res. 34, 531.546 (1976).

[23] Payne, A. I. L., Gulland, J. A. \& Brink, K. H. (eds.) The Benguela and comparable ecosystems. (South African Journal of Marine Science, Cape Town, 1987).

[24] Kidd, R. \& Sander, F. Influence of the Amazon River discharge on the marine production system off Barbados. Journal of Marine Res. 37, 669-681 (1979).
[25] Riley, G. A. The significance of the Mississippi River drainage for biological conditions in the northern Gulf of Mexico. J. of Mar. Res. 1 (1937).

[26] Levine, J. S. (ed.) Global Biomass Burning: Atmospheric, Climatic and Biospheric Implications. (The MIT Press, Cambridge, London, 1991).

[27] McTainsh, G. H. Quaternary aeolian dust processes and sediments in the Australiein region. Quaternary Science Reviews 8, 235-253 (1989).

[28] Comiso, J. C., McClain, C. R., Sullivan, C. W., Ryan, J. P. \& Leonard, C. L. Coastal Zone Color Scanner pigment concentrations in the Siouthern Ocean and relationships to geophysical surface features. J. Geophys. Res. 98, 2,419-2,451 (1993).

[29] Wilson, C. A global view of bio-physical coupling from SeaWiFS and TOPEX satellite data, 1997-2001. Geophys. Res. Lett. 29, 98:1-4 (2002).

[25] Charison, R. J. in Earth System Science: from Biogeochemical Cycles to Global Change (eds. Jacobson, M. C., Charlson, R. J., Rodhe, H. \& Orians, G. H.) 132-158 (Academic Press, London, 2000). 